\title{
TERMINATIONS OF PALMAR MAIN LINES AND MAIN- LINE INDICES IN 47, XXY KLINEFELTER'S SYNDROME
}

\author{
Yosuke Komatz and Osamu Yoshida \\ Department of Urology, Faculty of Medicine, \\ Kyoto University, Sakyo-ku, Kyoto 606, Japan
}

\begin{abstract}
Summary Terminations of the main lines and the main-line indices were examined on the palm prints of 65 patients with 47, XXY Klinefelter's syndrome. No significant differences were observed between the patient and control groups as far as the termination frequency for each main line was concerned. A significant bimanual difference was noted for all the main lines among the controls, but not for main lines $\mathrm{D}$ and $\mathrm{C}$ in the patient group. Additionally, the bimanual difference of the main-line index was definitely of smaller magnitude in the Klinefelter's syndrom group than among the controls, indicating less asymmetry.
\end{abstract}

Various dermatoglyphic traits have been studied in 47, XXY Klinefelter's syndrome. However, information has been scarce concerning the palmar main lines in this sex chromosomal abberation. In 1969, Cushman and Soltan reported on 20 dermatoglyphic traits in 55 cases of Klinefelter's syndrome. In connection with the palmar main lines, however, they only mentioned that the frequency of absent and abortive palmar c triradii did not differ between the patients and the controls. In this paper, the frequency of terminations of the palmar main lines and the main-line indices of 65 cases of 47, XXY Klinefelter's syndrome are examined and compared with those of normal male and female controls.

\section{MATERIALS AND METHODS}

The subjects of this study were 65 Klinefelter's syndrome patients, ranging between the ages of 19 and 46, seen at the Infertility Clinic of the Department of Urology, Kyoto University Hospital. In all cases, the karyotype was determined by peripheral blood culture to be $47, \mathrm{XXY}$. The controls were 100 males and 100 females with no major phenotypic anomalies. The males ranged from 19 to 59 years of age and the females from 19 to 42 .

The palm prints were collected using a standard technique, good quality paper and printer's ink. The classification of the terminations of the main lines was made 
Table 1. Percentage frequencies of terminations of the palmar main lines in patients with Klinefelter's syndrome and controls.

\begin{tabular}{|c|c|c|c|c|c|c|c|c|c|c|}
\hline \multirow[t]{2}{*}{$\begin{array}{l}\text { Main } \\
\text { lines }\end{array}$} & \multirow[t]{2}{*}{$\begin{array}{l}\text { Termi- } \\
\text { nations }\end{array}$} & \multicolumn{3}{|c|}{$\begin{array}{c}\text { Klinefelter's } \\
\text { syndrome } \\
n=65\end{array}$} & \multicolumn{3}{|c|}{$\begin{array}{c}\text { Male } \\
\text { controls } \\
n=100\end{array}$} & \multicolumn{3}{|c|}{$\begin{array}{l}\text { Female } \\
\text { controls } \\
n=100\end{array}$} \\
\hline & & $\mathbf{L}$ & $\mathrm{R}$ & $\mathbf{L}+\mathbf{R}$ & $\mathrm{L}$ & $\mathrm{R}$ & $\mathbf{L}+\mathbf{R}$ & L & $\mathbf{R}$ & $\mathrm{L}+\mathrm{R}$ \\
\hline \multirow[t]{6}{*}{ D } & 7 & 44.6 & 35.4 & 40.0 & 43.0 & 27.0 & 35.0 & 55.0 & 28.0 & 41.5 \\
\hline & 8 & - & - & - & 1.0 & 2.0 & 1.5 & 1.0 & 1.0 & 1.0 \\
\hline & 9 & 35.4 & 35.4 & 35.4 & 36.0 & 39.0 & 37.5 & 28.0 & 44.0 & 36.0 \\
\hline & 11 & 18.5 & 29.2 & 23.8 & 13.0 & 32.0 & 22.5 & 16.0 & 27.0 & 21.5 \\
\hline & $X$ & 一 & - & - & 6.0 & - & 3.0 & - & - & - \\
\hline & O & 1.5 & - & 0.8 & 1.0 & - & 0.5 & - & - & - \\
\hline \multirow[t]{8}{*}{ C } & $5^{\prime}$ & 9.2 & 3.1 & 6.2 & 8.0 & - & 4.0 & 8.0 & 1.0 & 4.5 \\
\hline & $5^{\prime \prime}$ & 36.9 & 27.7 & 32.3 & 39.0 & 28.0 & 33.5 & 46.0 & 22.0 & 34.0 \\
\hline & 6 & - & - & - & 1.0 & 2.0 & 1.5 & 1.0 & 1.0 & 1.0 \\
\hline & 7 & 27.7 & 24.6 & 26.2 & 27.0 & 27.0 & 27.0 & 20.0 & 38.0 & 29.0 \\
\hline & 9 & 6.2 & 24.6 & 15.4 & 7.0 & 32.0 & 19.5 & 10.0 & 24.0 & 17.0 \\
\hline & 11 & - & 3.1 & 1.5 & 2.0 & 3.0 & 2.5 & - & - & - \\
\hline & $\mathrm{X}$ & 7.7 & 9.2 & 8.5 & 14.0 & 7.0 & 10.5 & 5.0 & 10.0 & 7.5 \\
\hline & $\mathrm{O}$ & 12.3 & 7.7 & 10.0 & 2.0 & 1.0 & 1.5 & 10.0 & 4.0 & 7.0 \\
\hline \multirow[t]{7}{*}{ B } & 3 & 1.5 & 1.5 & 1.5 & 1.0 & - & 0.5 & 3.0 & - & 1.5 \\
\hline & 4 & 1.5 & - & 0.8 & 1.0 & - & 0.5 & 1.0 & 1.0 & 1.0 \\
\hline & $5^{\prime}$ & 56.9 & 26.2 & 41.5 & 52.0 & 35.0 & 43.5 & 41.0 & 22.0 & 31.5 \\
\hline & $5^{\prime \prime}$ & 24.6 & 38.5 & 31.5 & 30.0 & 32.0 & 31.0 & 38.0 & 47.0 & 42.5 \\
\hline & 7 & 13.8 & 30.8 & 22.3 & 14.0 & 30.0 & 22.0 & 17.0 & 30.0 & 23.5 \\
\hline & 9 & - & 3.1 & 1.5 & 2.0 & 3.0 & 2.5 & - & - & - \\
\hline & 11 & 1.5 & - & 0.8 & - & - & 一 & 一 & - & - \\
\hline \multirow[t]{6}{*}{ A } & 1 & 18.5 & 4.6 & 11.5 & 9.0 & 1.0 & 5.0 & 15.0 & 1.0 & 8.0 \\
\hline & 2 & 一 & - & - & 1.0 & 1.0 & 1.0 & - & - & - \\
\hline & 3 & 73.8 & 56.9 & 65.4 & 85.0 & 75.0 & 80.0 & 77.0 & 76.0 & 76.5 \\
\hline & 4 & 1.5 & 12.3 & 6.9 & 1.0 & 11.0 & 6.0 & 5.0 & 4.0 & 4.5 \\
\hline & $5^{\prime}$ & 6.2 & 26.2 & 16.2 & 4.0 & 9.0 & 6.5 & 3.0 & 18.0 & 10.5 \\
\hline & $5^{\prime \prime}$ & - & - & - & - & 3.0 & 1.5 & - & 1.0 & 0.5 \\
\hline
\end{tabular}

by Penrose's system (1968), while Cummins' index (1936) was used as the main-line index.

\section{RESULTS}

Main line termination frequencies are presented in Table 1.

\section{Main line $D$}

Termination frequency for main line $\mathrm{D}$ was high in position 7 , moderate in position 9 and low in position 11 in the left hands of both the patients and the control groups. The order was inverse in position 7 and 9 in the right hands of the male and female controls, while the frequencies were the same in the right hands of the patients.

No bimanual difference was found in the Klinefelter's syndrome group $\left(\chi^{2}=\right.$ 
2.28, d.f. $=2,0.30<p)$, but was significant among the control males $\left(\chi^{2}=11.60\right.$, d.f. $=2, \mathrm{p}<0.01)$ and female $\left(\chi^{2}=15.16\right.$, d.f. $\left.=2, p<0.001\right)$.

However, there was no significant differences between the right and left hands, respectively, of the patients and control groups.

\section{Main line $C$}

Main line $C$ running toward the ulnar side such as position $5^{\prime}, 5^{\prime \prime}$ and 7 and toward the radial side such as position 9 and 11 occurs at the frequencies of $64.7 \%$ and $16.9 \%$, respectively, in both hands of patients with Klinefelter's syndrome. This line was abortive in $8.5 \%$ of the patients and was totally absent in $10 \%$. It tended to run more to the radial side in the right hand than in the left, while total absence of the line was more frequent in the left hand than in the right.

In the control group, the ulnar type was more frequently observed, with the left hand tending to have more radial types than the right. The abortive or absent line was more often observed in the left hand than in the right.

To carry out statistical tests, main line $\mathrm{C}$ terminations were divided into three groups: $\left(5^{\prime}, 5^{\prime \prime}\right),(6,7)$ and $(9,11, X, 0)$. No bimanual difference was found in the Klinefelter's group $\left(\chi^{2}=5.24\right.$, d.f. $\left.=2,0.05<p<0.10\right)$, but it was significant in the control males $\left(\chi^{2}=9.56\right.$, d.f. $\left.=2, p<0.01\right)$ and females $\left(\chi^{2}=20.56\right.$, d.f. $=2, p<$ 0.001).

No significant difference-was noted in either hand between the Klinefelter's syndrome patients and the control group.

\section{Main line $B$}

The frequency of terminations of main line B was, in the order of position, $5^{\prime}$, $5 "$, and 7 in both hands of the patients and the male controls and in the left hands of the female controls.

There was a significant bimanual difference in the Klinefelter's syndrome group $\left(\chi^{2}=13.52\right.$, d.f. $\left.=2, p<0.01\right)$ as well as in the control males $\left(\chi^{2}=9.20\right.$, d.f. $=2,0.01$ $<\mathrm{p}<0.02)$ and females $\left(\chi^{2}=10.24\right.$, d.f. $\left.=2, \mathrm{p}<0.01\right)$.

However, no significant difference was noted in either hand between the patient and control groups.

\section{Main line $A$}

The frequency of terminations of main line A among the patients with Klinefelter's syndrome was, in the order of position, $3,5^{\prime}$ and 1 in both hands. At positions $5^{\prime}$ and 4 , the frequency was higher in the right hand than in the left, while the contrary was the case for positions 1 and 3 . At position 1 , the frequency was $18.5 \%$ in the left hand, while it was only $4.6 \%$ in the right hand.

Among the controls, position 3 showed the highest frequency in each hand. The frequency of position $5^{\prime}$ was higher and that of position 1 was lower in the right hand than the"left. 
Table 2. Mean main-line indices in patients with Klinefelter's syndrome and controls.

\begin{tabular}{llcccc}
\hline & & Left hand & Right hand & $\begin{array}{c}\text { Bimanual } \\
\text { difference }\end{array}$ & Both hand \\
\hline $\begin{array}{c}\text { Klinefelter's } \\
\text { syndrome }\end{array}$ & mean & $6.22 \pm 0.22$ & $7.43 \pm 0.25$ & $1.21 \pm 0.04$ & $13.58 \pm 0.39$ \\
$\mathrm{n}=65$ & range & $3-11$ & $5-11$ & & $8-20$ \\
Male controls & mean & $5.99 \pm 0.17$ & $7.49 \pm 0.19$ & $1.50 \pm 0.03$ & $13.48 \pm 0.31$ \\
$\mathrm{n}=100$ & range & $1-9$ & $3-12$ & & $6-21$ \\
Female controls & mean & $5.99 \pm 0.18$ & $7.31 \pm 0.19$ & $1.32 \pm 0.03$ & $13.30 \pm 0.30$ \\
$\mathrm{n}=100$ & range & $3-11$ & $5-12$ & & $8-23$ \\
\hline
\end{tabular}

For statistical tests, main line A terminations were divided into two groups: $(1,3)$ and $\left(4,5^{\prime}\right)$. There was a significant bimanual difference in both the patient group $\left(\chi^{2}=17.30\right.$, d.f. $\left.=1, \mathrm{p}<0.001\right)$ as well as among the controls (males: $\chi^{2}=10.86$, d.f. $=1, \mathrm{p}<0.001$; females: $\chi^{2}=6.43,0.01<\mathrm{p}<0.02$ ).

No significant difference were observed in either hand between the Klinefelter's patients and the control group.

Main-line indices are shown in Table 2.

The mean values of the main-line indices of the Klinefelter's group were $6.22 \pm$ $0.22,7.43 \pm 0.25$ and $13.58 \pm 0.39$ in the left, right and both hands, respectively. Statistical comparison was carried out by the Student's $t$ test. No significant difference was observed in each comparison between the patients and the controls. On the contrary, the bimanual difference was significant among the patients with Klinefelter's syndrome and the mean value of the right hand was higher than that of the left $(\mathrm{p}<$ $0.001)$. The same tendency was found among the control males and females $(p<$ 0.001 for both). The bimanual differences of the mean main-line indices were 1.21, 1.50 and 1.32 in these three populations and they were all significantly different $(\mathrm{p}<$ $0.001)$.

\section{DISCUSSION}

Racial differences in the frequency of the palmar main lines were shown in a comparison of modal types of main line D (Cummins and Midlo, 1926) and of modal types of main line C (Plato, 1970a). For instance, among the modal types of main line $D$, type 7 is most frequently observed among the Japanese (Kasai, 1951) and least frequently among Caucasians (Holt, 1968). Among the modal types of main line $\mathrm{C}$, the ulnar type outnumbers the radial type among the Japanese, while the opposite holds true for Caucasians (Plato, 1970a).

It is said that the courses of the palmar ridges of the male tend to be more transverse than those of the female (Plato, 1970b; Floris, 1975).

In addition, main line terminations tend to be bimanually asymmetrical, with their courses more transverse in the right than in the left hand. Main line A of the 
right hand often terminates in the distal part of the ulnar margin of the palm. Main line $\mathrm{D}$ of the right hand tends to terminate more radially than that of the left hand. Main line $\mathrm{C}$ is more frequently abortive or absent in the left hand than the right (Schaumann and Alter, 1976).

Our present study on 65 cases of Klinefelter's syndrome failed to reveal significant differences between the patients and the controls in the terminations of main lines $D, C, B$ and $A$ in each hand.

An interesting finding in connection with Klinefelter's syndrome, however, was reduced bimanual difference in the frequency of terminations of main lines $D$ and $C$, when compared with the controls. In the latter group, these bimanual differences were significant.

This tendency was also observed in the main-line index. The bimanual difference of the mean main-line indices was the largest in the normal male, followed by normal female and, finally, the patient group, indicating that the XXY cases are more symmetrical as far as the main-line index is concerned.

In connection with terminations of the palmar main lines in Klinefelter's syndrome, Wiśniewski et al. (1969) reported that there was bimanual symmetry in the terminations of main lines C, B and A. Their observations are confirmed by the present study.

An increased frequency of thenar exit (position 1) of main line $\mathrm{A}$ and abortive or absent main line $\mathrm{C}$ is present in various congenital abnormalities (Preus and Fraser, 1972). However, no such findings were obtained in the present study.

\section{REFERENCES}

Cummins, H. and Midlo, C. 1926. Palmar and planter epidermal ridge configurations (dermatoglyphics) in European-Americans. Amer. J. Phys. Anthrop. 9: 471-502.

Cummins, H. 1936. Methodology in palmar dermatoglyphics. Middle American Research Series, Tulane University, Publ. 7: 23-8,1.

Cushman, C.J. and Soltan, H.C. 1969. Dermatoglyphics in Klinefelter's syndrome (47,XXY). Hum. Hered. 19: 641-653.

Floris, G. 1975. Sex and side differences and correlations between quantitative palmar characteristics in a sample Sardinian population. Amer. J. Phys. Anthrop. 42: 277-280.

Holt, S.B. 1968. The Genetics of Dermal Ridges, Charles C Thomas, Springfield, Illinois.

Kasai, K. 1951. Report on the investigation of palmar patterns in 2500 Japanese. Jap. J. Legal Med. $5:$ 140-146.

Penrose, L.S. 1968. Memorandum on dermatoglyphic nonmenclature. Birth Defects Original Article Series, Vol. 4, No. 3, The National Foundation-March of Dimes, New York.

Plato, C.C. 1970a. Polymorphism of the $C$ line of palmar dermatoglyphics with a new classification of the C line terminations. Amer. J. Phys. Anthrop. 33:413-420.

Plato, C.C. 1970b. Dermatoglyphics and flexion creases of the Cypriots. Amer. J. Phys. Anthrop. 33: $421-428$.

Preus, M. and Fraser, F.C. 1972. Dermatoglyphics and syndromes. Amer. J. Dis. Child. 124: 933-943.

Schaumann, B. and Alter, M. 1976. Delmatoglyphics in Medical Disorders. Springer-Verlag, New York. 
Wiśniewski, L., Bartnik, B., Gawrońska, H., Korsak, E. and Dzieszko-Lebensztejn, T. 1969. Behaviour of palmar dermatoglyphs in syndromes with chromosomal aberrations. Genet. Polonica 10: $316-322$. 